\title{
Trajectory-Tracking Control for Manipulators Based on Fuzzy Equivalence and a Terminal Sliding Mode
}

\author{
Youyu Liu1,2,* - Yi Li1,2 - Xuyou Zhang1,2 - Bo Chen ${ }^{1,2}$ \\ ${ }^{1}$ Key Laboratory of Advanced Perception and Intelligent Control of High-end Equipment, Ministry of Education, China \\ 2 Anhui Polytechnic University, School of Mechanical Engineering, China
}

To suppress the chattering of manipulators under heavy-load operations, a control method called fuzzy equivalence \& terminal sliding mode (FETSM) was applied to the trajectory tracking of motion curves for manipulators. Based on the switching term of the equivalent sliding mode (ESM), a fuzzy parameter matrix processed by the simple fuzzy rules was introduced, and the fuzzy switching term was obtained. By summing the fuzzy switching term and the equivalent term of the equivalence and a terminal sliding mode (ETSM), the control law of the FETSM for manipulators was obtained. On this basis, the stability of the system was analysed and the finite arrival time of it was deduced. On the premise of ensuring the stability of the system, the fuzzy rules and membership functions were designed for the fuzzy constants in the fuzzy switching term. Simulation tests show that the proposed FETSM can ensure sufficient trajectory-tracking precision, error convergence speed, and robustness. Compared with the ETSM, the proposed FETSM can reduce the chattering time by $94.75 \%$ on average; compared with the proportion-integral-differential (PID) control method, the maximum chattering amplitude by the FETSM can be reduced by at least $99.21 \%$. Thus, the proposed FETSM is suitable for those manipulators under heavy-load operations.

Keywords: sliding mode control, fuzzy switch term, chattering, manipulator, trajectory tracking

\section{Highlights}

- The law of the FETSM control system for manipulators is obtained.

- The stability and finite arrival time of the FETSM system are proved.

- Fuzzy rules are used to estimate the external disturbances of the system and uncertainties of the system.

- The chattering of the sliding mode system can be suppressed by the proposed control method.

\section{INTRODUCTION}

Manipulator is a non-linear and time-varying system with multi-input, multi-output, strong coupling, in which there are usually uncertain modelling and external disturbances [1] and [2]. Moreover, the trajectory tracking of motion curves for manipulators has always been a hot and difficult topic. Manipulators are mostly used for heavy-load operations, such as palletizing, handling, and so on, in which small chattering and high torque control ability are required, while the trajectory tracking precision and robustness requirements are insignificant [3]. At this present, some control methods are used in trajectory tracking for manipulators, mainly including sliding mode control [4] and [5], neural network control [6] to [8], the proportional-integral-derivative (PID) control [9] to [11] and robust control [12] and [13]. In order to reduce the chattering of manipulators under heavy-load operations, a fuzzy equivalence and a terminal sliding mode (FETSM) control method for manipulators has been proposed in this article.

Sliding mode control has been receiving increasing attention due to its characteristics of fast response and small influence by parameter changing and external disturbances. However, there is a serious chattering phenomenon in sliding mode control, which affects the stability of trajectorytracking system and increase energy consumption. In order to overcome the chattering of the sliding mode system for manipulators, researchers have conducted some studies. For example, Liu et al. [14] constructed an approaching law with $f a l$ function to adjust the speed of approaching motion. When the state is far from the sliding mode surface of system, the speed of approaching motion is faster; when the state is close to the sliding mode surface, the speed decreases greatly. Therefore, the system can pass through the sliding mode surface at a lower speed to reduce its chattering. However, it is not easy to select the deceleration position. The overall time of approaching motion will be increased if the position chosen is too far from the sliding mode surface; otherwise, the chattering will be increased to a certain extent. Combining with the dynamic surface, which prevented the complex differential of the virtual control laws, Jiang et al. [15] designed a fuzzy adaptive system to approximate the observation errors of the uncertain disturbances and to reduce the chatter of the control law. The fuzzy parameters and fuzzy rules of this method are complex, which will reduce the computational efficiency. Xi et al. [16] set 
the deceleration position change with the state of the sliding mode system by using fuzzy rules to deal with the exponent in power approach laws and replaced sign functions with hyperbolic tangent functions. This method can reduce the approaching time of the sliding mode system and the chattering of them. However, the chattering of the sliding mode system is still at a high level; consequently, some constants are still set to offset the disturbances and uncertainties. Tran et al. [17] used radial basis function neural networks to approximate the unknown non-linear dynamics of the system and designed an adaptive compensation mechanism of approximation error and adaptive law of weights of neural networks to realize model-free control. Chang et al. [18] proposed an adaptive sliding mode control scheme by introducing an adaptive term derived from a radical basis function network, which does not require knowledge of the bound of the system uncertainties and external disturbances. It simultaneously eliminates the chattering phenomenon without deteriorating the system fast-response characteristic and robustness. The chattering of the system is reduced by the above two methods. However, with the increase of the degree of freedom (DOF) of manipulators, the number of parameters in each matrix in a controlled model increases geometrically, which will lead to a significant increase in the computational complexity and the time required to control the system.

In this article, the FETSM control method is proposed. a fuzzy parameter matrix is introduced into the switching term of the equivalent sliding mode (ESM), and the matrix is processed with simple fuzzy rules, so that it can approach the sum of the uncertainties and external disturbances to the greatest degree possible while ensuring the stability of the system. The purpose is to reduce chattering and optimize the input torque control of manipulators under heavy-load operations on the premise of ensuring sufficient joint control precision, error convergence speed, and robustness. The feasibility and effectiveness of the proposed method are verified by comparing the trajectory tracking and input torque with several existing methods.

\section{DESIGN ON CONTROL LAW OF FETSM}

In order to obtain the control law of the FETSM, the equivalence term and the fuzzy switching term need to be designed. The former makes the trajectory tracking move on the sliding mode surface, and the latter is used to offset the uncertainties and external disturbances to ensure that the state of the trajectory-tracking system moves towards the sliding mode surface.

\subsection{Design on Equivalent Term}

The dynamic equation of $N$-DOF manipulator can be described as follows [19]:

$$
\mathbf{M}(\mathbf{q}) \ddot{\mathbf{q}}+\mathbf{V}(\mathbf{q}, \dot{\mathbf{q}}) \dot{\mathbf{q}}+\mathbf{G}(\mathbf{q})+\Delta(\mathbf{q}, \dot{\mathbf{q}})+\mathbf{d}=\tau,
$$

where $\mathbf{q}$ is an $N$-dimensional joint position vector; $\dot{\mathbf{q}}$ is the first-order derivative of $\mathbf{q}$. $\ddot{\mathbf{q}}$ is the second-order derivative of $\mathbf{q}$. $\mathbf{M}(\mathbf{q})$ is an $N$-order symmetric positive definite inertial matrix; $\mathbf{V}(\mathbf{q}, \dot{\mathbf{q}})$ is an $N$-order centrifugal force matrix; $\mathbf{G}(\mathbf{q})$ is an $N$-dimensional gravity vector; $\Delta(\mathbf{q}, \dot{\mathbf{q}})=\left[\Delta_{1}, \Delta_{2}, \ldots, \Delta_{N}\right]^{\mathrm{T}}$ is the uncertainties of modelling and friction; $\mathbf{d}=\left[d_{1}, d_{2}, \ldots, d_{N}\right]^{\mathrm{T}}$ is an $N$-dimensional external disturbance, and $\|\Delta(\mathbf{q}, \dot{\mathbf{q}})+\mathbf{d}\| \leq \Delta+d ; \quad \boldsymbol{\tau} \quad$ is an $N$-dimensional joint input torque.

$\mathbf{M}(\mathbf{q})$ is an invertible matrix because $\mathbf{M}(\mathbf{q})$ is a symmetric positive definite inertia matrix. From Eq. (1),

$$
\ddot{\mathbf{q}}=\mathbf{M}^{-1}(\mathbf{q})[\tau-\mathbf{V}(\mathbf{q}, \dot{\mathbf{q}}) \dot{\mathbf{q}}-\mathbf{G}(\mathbf{q})-\Delta(\mathbf{q}, \dot{\mathbf{q}})-\mathbf{d}] .
$$

Order $\mathbf{x}_{1}=\mathbf{q}$ and $\mathbf{x}_{2}=\dot{\mathbf{q}}$, the dynamics equation of manipulators can be inferred from Eq. (2), namely,

$$
\left\{\begin{array}{rl}
\dot{\mathbf{x}}_{1}= & \mathbf{x}_{2} \\
\dot{\mathbf{x}}_{2} & =\mathbf{M}^{-1}\left(\mathbf{x}_{1}\right) \\
& \cdot\left[\tau-\mathbf{V}\left(\mathbf{x}_{1}, \mathbf{x}_{2}\right) \mathbf{x}_{2}-\mathbf{G}\left(\mathbf{x}_{1}\right)-\Delta\left(\mathbf{x}_{1}, \mathbf{x}_{2}\right)-\mathbf{d}\right]
\end{array} .\right.
$$

Order $\mathbf{e}=\mathbf{q}_{d}-\mathbf{x}_{1} \quad\left(\mathbf{q}_{d}\right.$ is the desired position trajectory of joints), a non-linear sliding surface is designed as follows [20]:

$$
\mathbf{s}=\mathbf{e}+\beta^{-1} \dot{\mathbf{e}}^{\frac{p}{q}} .
$$

where $\mathbf{e}$ is the position tracking error of joints; $\boldsymbol{\beta}=\operatorname{diag}\left\{\beta_{1}, \beta_{2}, \ldots, \beta_{N}\right\}$, and $\beta_{1}, \beta_{2}, \ldots, \beta_{N}>0 ; p$ and $q$ are odd numbers, and $p>q, 1<p / q<2$.

Taking the derivative of Eq. (4), then,

$$
\dot{\mathbf{s}}=\dot{\mathbf{e}}+\frac{p}{q} \boldsymbol{\beta}^{-1} \operatorname{diag}\{\ddot{\mathbf{e}}\} \dot{\mathbf{e}}^{\frac{p-q}{q}},
$$

where $\operatorname{diag}\{\ddot{\mathbf{e}}\}$ is an $N$-order diagonal matrix in which the principal diagonal elements are the corresponding elements of $\ddot{\mathbf{e}}$.

Let $\dot{\mathbf{s}}=0$, thus,

$$
\dot{\mathbf{e}}+\frac{p}{q} \boldsymbol{\beta}^{-1} \operatorname{diag}\left\{\ddot{\mathbf{q}}_{d}-\dot{\mathbf{x}}_{2}\right\} \dot{\mathbf{e}}^{\frac{p-q}{q}}=0 .
$$


Ignoring the uncertainties and external disturbances, and substituting Eq. (3) into Eq. (6),

$$
\begin{aligned}
& \dot{\mathbf{e}}+\frac{p}{q} \boldsymbol{\beta}^{-1} \operatorname{diag}\left\{\ddot{\mathbf{q}}_{d}-\mathbf{M}^{-1}\left(\mathbf{x}_{1}\right)\right. \\
&\left.\cdot\left[\tau-\mathbf{V}\left(\mathbf{x}_{1}, \mathbf{x}_{2}\right) \mathbf{x}_{2}-\mathbf{G}\left(\mathbf{x}_{1}\right)\right]\right\} \dot{\mathbf{e}}^{\frac{p-q}{q}}=0
\end{aligned}
$$

From Eq. (7),

$$
\begin{aligned}
& \operatorname{diag}\{\left\{\ddot{\mathbf{q}}_{d}-\mathbf{M}^{-1}\left(\mathbf{x}_{1}\right)\right. \\
&\left.\cdot\left[\tau-\mathbf{V}\left(\mathbf{x}_{1}, \mathbf{x}_{2}\right) \mathbf{x}_{2}-\mathbf{G}\left(\mathbf{x}_{1}\right)\right]\right\}=-\frac{q}{p} \beta \dot{\mathbf{e}}^{2-\frac{p}{q}} .
\end{aligned}
$$

$\operatorname{diag}^{-1}$ is defined as an operation that has the following characteristics: If $\boldsymbol{\Lambda}=\operatorname{diag}\left\{\Lambda_{1}, \Lambda_{2}, \ldots, \Lambda_{N}\right\}$ is a diagonal matrix, then,

$$
\operatorname{diag}^{-1}\{\Lambda\}=\left[\Lambda_{1}, \Lambda_{2}, \ldots, \Lambda_{N}\right]^{\mathrm{T}}
$$

Both sides of Eq. (8) are diagonal matrices. From Eqs. (8) and (9),

$$
\begin{gathered}
\ddot{\mathbf{q}}_{d}-\mathbf{M}^{-1}\left(\mathbf{x}_{1}\right)\left[\tau-\mathbf{V}\left(\mathbf{x}_{1}, \mathbf{x}_{2}\right) \mathbf{x}_{2}-\mathbf{G}\left(\mathbf{x}_{1}\right)\right] \\
=\operatorname{diag}^{-1}\left(-\frac{q}{p} \boldsymbol{\beta} \dot{\mathbf{e}}^{2-\frac{p}{q}}\right) .
\end{gathered}
$$

From Eq. (10), the equivalent term can be designed as Eq. (11),

$$
\begin{aligned}
\tau_{e q} & =\mathbf{M}\left(\mathbf{x}_{1}\right)\left[\ddot{\mathbf{q}}_{d}+\operatorname{diag}^{-1}\left(\frac{q}{p} \beta \dot{\mathbf{e}}^{2-\frac{p}{q}}\right)\right] \\
& +\mathbf{V}\left(\mathbf{x}_{1}, \mathbf{x}_{2}\right) \mathbf{x}_{2}+\mathbf{G}\left(\mathbf{x}_{1}\right) .
\end{aligned}
$$

\subsection{Design on Fuzzy Switching Term}

In order to ensure that it can compensate uncertainties and external disturbances, the fuzzy switching term is designed as follows,

$$
\begin{aligned}
\tau_{s w} & =\operatorname{diag}\left\{\varepsilon_{1}, \varepsilon_{2}, \ldots, \varepsilon_{N}\right\} \\
& \cdot \operatorname{diag}\left\{\kappa_{1}, \kappa_{2}, \ldots, \kappa_{N}\right\} \operatorname{sgn}(\mathbf{s}),
\end{aligned}
$$

where $\operatorname{diag}\left\{\kappa_{1}, \kappa_{2}, \ldots, \kappa_{N}\right\}$ is a constant matrix, and $\kappa_{1}, \kappa_{2}, \ldots, \kappa_{N} \geq \Delta+d, \quad \kappa=\max (|d(t)|)+\eta$; $\operatorname{diag}\left\{\varepsilon_{1}, \varepsilon_{2}, \ldots, \varepsilon_{N}\right\}$ is a fuzzy parameter matrix $\left(\boldsymbol{\tau}_{s w}\right.$ is a basic switching item when $\varepsilon_{1}, \varepsilon_{2}, \ldots, \varepsilon_{N}$ are all equal to 1 , and $\boldsymbol{\tau}_{s w}$ is a fuzzy switching item while one of $\varepsilon_{1}, \varepsilon_{2}, \ldots, \varepsilon_{N}$ is not equal to $1 ;$ and $\varepsilon_{1} \kappa_{1}, \varepsilon_{2} \kappa_{2}, \ldots, \varepsilon_{N} \kappa_{N} \geq \Delta+d$; sgn is a symbolic function [21], and $\operatorname{sgn}(\mathbf{s})=\left[\operatorname{sgn}\left(s_{1}\right), \operatorname{sgn}\left(s_{2}\right), \ldots, \operatorname{sgn}\left(s_{N}\right)\right]^{\mathrm{T}}$. If $Z$ is a real number, then, $\operatorname{sgn}(Z)=\left\{\begin{array}{c}1, Z>0 \\ 0, Z=0 \\ -1, Z<0\end{array}\right.$.

Order $\quad \boldsymbol{\kappa}=\operatorname{diag}\left\{\kappa_{1}, \kappa_{2}, \ldots, \kappa_{N}\right\} \quad$ and $\boldsymbol{\varepsilon}=\operatorname{diag}\left\{\varepsilon_{1}, \varepsilon_{2}, \ldots, \varepsilon_{N}\right\}$, The control law of the FETSM can be obtained by adding Eq. (11) to Eq. (12).

$$
\begin{aligned}
\tau & =\mathbf{M}\left(\mathbf{x}_{1}\right)\left[\ddot{\mathbf{q}}_{d}+\operatorname{diag}^{-1}\left(\frac{q}{p} \beta \dot{\mathbf{e}}^{2-\frac{p}{q}}\right)\right] \\
& +\mathbf{V}\left(\mathbf{x}_{1}, \mathbf{x}_{2}\right) \mathbf{x}_{2}+\mathbf{G}\left(\mathbf{x}_{1}\right)+\boldsymbol{\varepsilon \kappa s g n}(\mathbf{s}) .
\end{aligned}
$$

\section{ANALYSIS ON STABILITY AND FINITE ARRIVAL TIME}

\subsection{Stability Analysis}

For the sliding mode control of a rigid manipulator, a Lyapunov function [22] was defined as follows:

$$
\mathbf{L}_{y}=\frac{1}{2} \mathbf{s}^{\mathrm{T}} \mathbf{s}
$$

taking the derivative of Eq. (14),

$$
\dot{\mathbf{L}}_{y}=\mathbf{s}^{\mathrm{T}} \dot{\mathbf{s}} \text {. }
$$

From Eqs. (3), (13) and (15),

$$
\begin{aligned}
& \dot{\mathbf{L}}_{y}=\mathbf{s}^{\mathrm{T}}\left\{\dot{\mathbf{e}}+\frac{p}{q} \boldsymbol{\beta}^{-1} \operatorname{diag}\left\{\ddot{\mathbf{q}}_{d}-\mathbf{M}^{-1}\left(\mathbf{x}_{1}\right)\right.\right. \\
& \left.\left.\cdot\left[\tau-\mathbf{V}\left(\mathbf{x}_{1}, \mathbf{x}_{2}\right) \mathbf{x}_{2}-\mathbf{G}\left(\mathbf{x}_{1}\right)-\Delta\left(\mathbf{x}_{1}, \mathbf{x}_{2}\right)-\mathbf{d}\right]\right\} \dot{\mathbf{e}}^{\frac{p-q}{q}}\right\} .
\end{aligned}
$$

Substituting Eq. (13) into Eq. (16) and simplifying it,

$$
\begin{aligned}
& \dot{\mathbf{L}}_{y}= \frac{p}{q}\left[\frac{1}{\beta_{1}}, \ldots, \frac{1}{\beta_{N}}\right] \mathbf{M}^{-1}\left(\mathbf{x}_{1}\right)\left(\dot{\mathbf{q}}_{d}-\mathbf{x}_{2}\right)^{\frac{p-q}{q}} \\
& \cdot\left\{\left(\Delta\left(\mathbf{x}_{1}, \mathbf{x}_{2}\right)+\mathbf{d}\right) \mathbf{s}^{\mathrm{T}}-\operatorname{diag}\{\boldsymbol{\varepsilon \kappa}|\mathbf{s}|\}\right\},
\end{aligned}
$$

where $|\mathbf{s}|$ is the absolute value of $\mathbf{s}$, namely $|\mathbf{s}|=\left[\left|s_{1}\right|,\left|s_{2}\right|, \ldots,\left|s_{N}\right|\right]^{\mathrm{T}}$.

For $1<p / q<2$, then $0<(p-q) / q<2$; and both $p$ and $q$ are positive odd numbers. Therefore, the elements of $\left(\dot{\mathbf{q}}_{d}-\mathbf{x}_{2}\right)^{\frac{p-q}{q}}$ are non-negative numbers. $\beta_{1}, \beta_{2}, \ldots, \beta_{N}$ are positive numbers and $\mathbf{M}^{\mathbf{- 1}}\left(\mathbf{x}_{1}\right)$ is a symmetric positive definite matrix, when $\mathbf{x}_{2} \neq \dot{\mathbf{q}}_{d}$, 


$$
\frac{p}{q}\left[\frac{1}{\beta_{1}}, \ldots, \frac{1}{\beta_{N}}\right] \mathbf{M}^{-1}\left(\mathbf{x}_{1}\right)\left(\dot{\mathbf{q}}_{d}-\mathbf{x}_{2}\right)^{\frac{p-q}{q}}>0 .
$$

The sign of $\dot{\mathbf{L}}_{y}$ is determined by the $N$-order diagonal matrix $\left(\boldsymbol{\Delta}\left(\mathbf{x}_{1}, \mathbf{x}_{2}\right)+\mathbf{d}\right) \mathbf{s}^{\mathrm{T}}-\operatorname{diag}\{\boldsymbol{\varepsilon \kappa}|\mathbf{s}|\}$, which is written in matrix form as follows:

$$
\begin{aligned}
& {\left[\Delta\left(\mathbf{x}_{1}, \mathbf{x}_{2}\right)+\mathbf{d}\right] \mathbf{s}^{\mathrm{T}}-\operatorname{diag}\{\boldsymbol{\varepsilon \kappa}|\mathbf{s}|\}} \\
& =\left[\begin{array}{ccc}
\left(\Delta_{1}+d_{1}\right) s_{1}-\varepsilon_{1} \kappa_{1}\left|s_{1}\right| & \cdots & 0 \\
\vdots & \ddots & \vdots \\
0 & \cdots & \left(\Delta_{N}+d_{N}\right) s_{N}-\varepsilon_{N} \kappa_{N}\left|s_{1}\right|
\end{array}\right] .(
\end{aligned}
$$

Due to $\left|s_{1}\right| \geq s_{1}, \ldots,\left|s_{N}\right| \geq s_{N}$, all of the principal diagonal elements of $\left(\boldsymbol{\Delta}\left(\mathbf{x}_{1}, \mathbf{x}_{2}\right)+\mathbf{d}\right) \mathbf{s}^{\mathrm{T}}-\operatorname{diag}\{\boldsymbol{\varepsilon} \mathbf{\kappa}|\mathbf{s}|\}$ are non-positive numbers. Moreover, when the fuzzy parameter matrix works normally, $\varepsilon_{1} \kappa_{1}, \varepsilon_{2} \kappa_{2}, \ldots, \varepsilon_{N} \kappa_{N} \geq \Delta+d$. Thus, $\dot{\mathbf{L}}_{y} \leq 0$.

When $\mathbf{x}_{2} \neq \dot{\mathbf{q}}_{d}$, the trajectory-tracking system employed by the FETSM is stable according to Lyapunov's second method [23]. In addition, the sliding mode surface of it is non-singular. Substituting Eq. (13) into Eq. (3),

$$
\begin{aligned}
\dot{\mathbf{x}}_{2}= & \ddot{\mathbf{q}}_{d}+\operatorname{diag}^{-1}\left[\frac{q}{p} \beta\left(\dot{\mathbf{q}}_{d}-\mathbf{x}_{2}\right)^{2-\frac{p}{q}}\right]+\mathbf{M}^{-1}\left(\mathbf{x}_{1}\right) \\
& \cdot\left\{\Delta\left(\mathbf{x}_{1}, \mathbf{x}_{2}\right)+\mathbf{d}-\operatorname{diag}[\operatorname{\varepsilon \kappa sgn}(\mathbf{s})]\right\},
\end{aligned}
$$

when $\mathbf{x}_{2}=\dot{\mathbf{q}}_{d}$, for $\ddot{\mathbf{e}}=\dot{\mathbf{q}}_{d}-\mathbf{x}_{2}$,

$$
\ddot{\mathbf{e}}=\mathbf{M}^{-1}\left(\mathbf{x}_{1}\right)\left\{\Delta\left(\mathbf{x}_{1}, \mathbf{x}_{2}\right)+\mathbf{d}-\operatorname{diag}\{\boldsymbol{\varepsilon \kappa s g n}(\mathbf{s})\}\right\} .
$$

When $\mathbf{s}>0, \ddot{\mathbf{e}}<0$, namely, $\dot{\mathbf{e}}$ will decrease rapidly. While $\mathbf{s}<0, \ddot{\mathbf{e}}>0$, namely, $\dot{\mathbf{e}}$ will increase rapidly. Obviously, $\mathbf{s}$ can reach 0 within a finite time when $\mathbf{x}_{2}=\dot{\mathbf{q}}_{d}$ [20]. Therefore, the sliding mode of the $N$-DOF manipulator with the FETSM control law exists and can be reached.

\subsection{Analysis on Finite Arrival Time}

Eq. (4) can be written in scalar form: $s_{j}=e_{j}+\beta_{j}\left(\dot{e}_{j}\right)^{\frac{p}{q}}$ $\mathrm{j}=1,2, \ldots, N$. Order $s_{j}=0$,

$$
e_{j}+\beta_{j}\left(\frac{\mathrm{d} e_{j}}{\mathrm{~d} t}\right)^{\frac{p}{q}}=0
$$

From Eq. (22),

$$
\mathrm{d} t=\left(-\frac{e_{j}}{\beta_{j}}\right)^{-\frac{q}{p}} \mathrm{~d} e_{j} .
$$

If the trajectory-tracking system spends time $t_{j}$ from $e_{j}(0) \neq 0$ to $e_{j}\left(t_{j}\right)=0$, then,

$$
\int_{0}^{t_{j}} \mathrm{~d} t=\int_{e_{j}(0)}^{0}\left(-\frac{e_{j}}{\beta_{j}}\right)^{-\frac{q}{p}} \mathrm{~d} e_{j} .
$$

From Eq. (24), The effective time to reach equilibrium state is as follows:

$$
t_{j}=\beta_{j} \frac{p}{p-q}\left(\frac{e_{j}(0)}{\beta_{j}}\right)^{\frac{p-q}{p}} .
$$

If $t_{\max }=\max \left\{t_{1}, t_{2}, \ldots, t_{N}\right\}$, the trajectory-tracking error of the system must reach 0 within $t_{\max }$, which is finite according to Eq. (25). Therefore, the trajectorytracking error of the system can reach 0 within a finite time.

\section{DESIGN ON FUZZY RULES AND SYSTEM STRUCTURE}

\subsection{Design on Fuzzy Rules}

Supposing there is no fuzzy parameter matrix $\varepsilon$ in Eq. (18), $\dot{\mathbf{L}}_{y} \leq 0$ is still proper for $\kappa_{1}, \kappa_{2}, \ldots, \kappa_{N}$ are constants and not less than $\Delta+d$.Therefore, the FETSM system of manipulators remains stable. In contrast, uncertainties and external disturbances are timevarying, and $\kappa_{1}, \kappa_{2}, \ldots, \kappa_{N}$ are constants. Therefore, constant matrix cannot follow the change of $\Delta\left(\mathbf{x}_{1}, \mathbf{x}_{2}\right)+\mathbf{d}$, which leads to every main diagonal element of $\kappa \operatorname{sgn}(s)$ always being large, and then the chattering of the sliding mode system is increased. On the premise of stability, the difference between the corresponding parameters of $\boldsymbol{\varepsilon \kappa s g n}(\mathbf{s})$ and $\Delta\left(\mathbf{x}_{1}, \mathbf{x}_{2}\right)+\mathbf{d}$ are as small as possible by using the fuzzy method to adjust $\boldsymbol{\varepsilon}$, so as to reduce the chattering.

$\mathrm{NE}, \mathrm{PO}$ and $\mathrm{ZE}$ are used to represent negative, positive and zero, respectively. The input and output of the fuzzy system are defined as follows:

$$
\left\{\begin{array}{l}
\text { input }: s_{j}=\{\mathrm{NE}, \mathrm{ZE}, \mathrm{PO}\} \\
\text { output }: \varepsilon_{j}=\{\mathrm{ZE}, \mathrm{PO}\}
\end{array}, \quad j=1,2, \ldots, N .\right.
$$

"If-then" statement [24] is used to define fuzzy rules between the input and output.

$$
\left\{\begin{array}{l}
\text { Rule } 3 j-2: \text { If } s_{j} \text { is NE then } \varepsilon_{j} \text { is PO } \\
\text { Rule } 3 j-1: \text { If } s_{j} \text { is ZE then } \varepsilon_{j} \text { is ZE . } \\
\text { Rule3 } j: \text { If } s_{j} \text { is PO then } \varepsilon_{j} \text { is PO }
\end{array}\right.
$$




\subsection{Design on Membership Function}

As for the input $s$, the membership function is designed as follows [25]: its domain is $[-1,1]$; NE is a trapezoidal membership function, $[-1,-1,-2 \times \sigma, 0]$; ZE is a triangular membership function, $[-2 \times \sigma, 0,2 \times \sigma]$; $\mathrm{PO}$ is a trapezoidal membership function, $[0,2 \times \sigma, 1,1]$. As for the output $\varepsilon$, the membership function is designed as follows [25]: its domain is $[0,1]$; $\mathrm{ZE}$ is a triangular membership function, $\left[0,1 \times 10^{-5}, 2\right]$; PO is a trapezoidal membership function, $[0,1,1,1]$. The $\sigma$ in the function represents the thickness of the boundary layer. When $-\sigma<s<\sigma, s$ and $\varepsilon$ belong to ZE. In addition, the variation range of the $\varepsilon$ is between $1 \times 10^{-5}$ and 1 . While the $s$ approaches the boundary layer, the $\varepsilon$ approaches 1 . Conversely, when the $s$ approaches 0 , the $\varepsilon$ approaches $1 \times 10^{-5}$; When the $s$ is outside the boundary layer, the $\varepsilon$ is 1 . The membership function curves of the input and output of the proposed control method are shown in Fig. 1 [26].

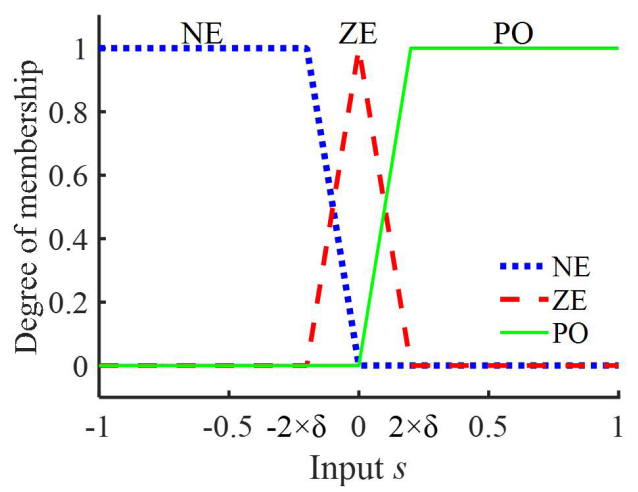

\subsection{System Structure}

The structure of the trajectory-tracking system of the FETSM for manipulators is shown in Fig. 2.

\section{SIMULATION VERIFICATION}

\subsection{Analysis on Trajectory Tracking}

MATLAB R2019b is applied as the simulation platform to track the ideal curve trajectories by using the FETSM, the ETSM [27], the ESM [28], and the PID [10] methods, respectively. By comparing the error of position tracking of each joint, the effects of the trajectory tracking of the above four control methods are analysed. Two curves are chosen as the ideal position curves of the joints 1 and 2. The coefficient of the curves is listed in Tables 1 to 4 . The

Fig. 1. The membership function of input and output of the FETSM; a) input $s ; b)$ output $\varepsilon$

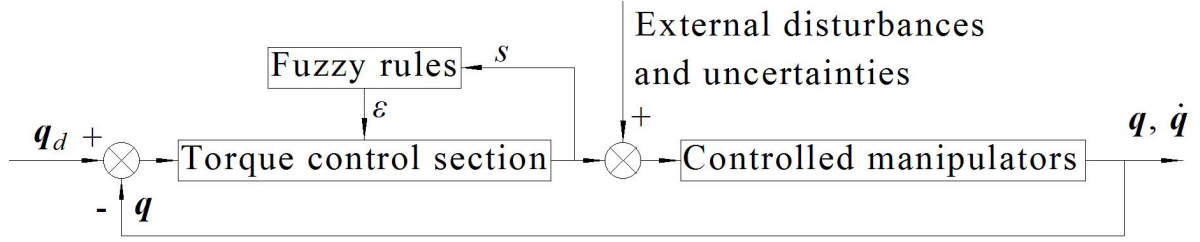

Fig. 2. Structure diagram of the FETSM trajectory-tracking system

Table 1. The coefficients of the 1 st position curve of the 1 st joint

\begin{tabular}{lccccc}
\hline Intervals [s] & $q_{4}[\mathrm{rad}]$ & $q_{3}[\mathrm{rad}]$ & $q_{2}[\mathrm{rad}]$ & $q_{1}[\mathrm{rad}]$ & 0.0000 \\
\hline$[0.0000,2.3806)$ & -0.0152 & 0.0731 & 0.0000 & -2.1338 & 0.0000 \\
\hline$[2.3806,3.5057)$ & 0.0243 & -0.3034 & 1.3445 & 4.2007 & -4.2699 \\
\hline$[3.5057,4.2751)$ & -0.0125 & 0.2120 & -1.3659 & 0.1554 & 0.0418 \\
\hline$[4.2751,6.6127)$ & 0.0005 & -0.0093 & 0.0535 & 4.6803 & -7.4387 \\
\hline$[6.6127,7.8886)$ & -0.0034 & 0.0942 & -0.9729 & -24.4928 & 50.0953 \\
\hline$[7.8886,10.2557)$ & 0.0114 & -0.3746 & 4.5742 & & \\
\hline
\end{tabular}


Table 2. The coefficients of the $1^{\text {st }}$ position curve of the $2^{\text {nd }}$ joint

\begin{tabular}{lccccc}
\hline Intervals [s] & $q_{4}[\mathrm{rad}]$ & $q_{3}[\mathrm{rad}]$ & $q_{2}[\mathrm{rad}]$ & $q_{1}[\mathrm{rad}]$ & 0.0000 \\
\hline$[0.0000,2.3806)$ & -0.0019 & 0.0093 & 0.0000 & $q_{0}[\mathrm{rad}]$ & 0.5236 \\
\hline$[2.3806,3.5057)$ & -0.0020 & 0.0101 & -0.0029 & 0.0045 & 0.5209 \\
\hline$[3.5057,4.2751)$ & 0.0136 & -0.2079 & 1.1433 & -2.6743 & 2.8686 \\
\hline$[4.2751,6.6127)$ & -0.0032 & 0.0796 & -0.7004 & 2.5805 & -2.7475 \\
\hline$[6.6127,7.8886)$ & -0.0010 & 0.0213 & -0.1216 & 0.0290 & 1.4707 \\
\hline$[7.8886,10.2557)$ & 0.0029 & -0.1033 & 1.3526 & -7.7240 & 16.7608 \\
\hline
\end{tabular}

Table 3. The coefficients of the $2^{\text {nd }}$ position curve of the 1 st joint

\begin{tabular}{lccccc}
\hline Intervals [s] & $q_{4}[\mathrm{rad}]$ & $q_{3}[\mathrm{rad}]$ & $q_{2}[\mathrm{rad}]$ & $q_{1}[\mathrm{rad}]$ & $q_{0}[\mathrm{rad}]$ \\
\hline$[0.0000,2.3806)$ & 0.0020 & -0.0097 & 0.0000 & 0.0000 & -0.3491 \\
\hline$[2.3806,3.5057)$ & -0.0017 & 0.0253 & -0.1249 & 0.1982 & -0.4670 \\
\hline$[3.5057,4.2751)$ & -0.0002 & 0.0051 & -0.0185 & -0.0503 & -0.2492 \\
\hline$[4.2751,6.6127)$ & -0.0029 & 0.0504 & -0.3096 & 0.7791 & -1.1356 \\
\hline$[6.6127,7.8886)$ & 0.0147 & -0.4147 & 4.3041 & -19.5600 & 32.4885 \\
\hline$[7.8886,10.2557)$ & -0.0094 & 0.3443 & -4.6773 & 27.6740 & -60.6644 \\
\hline
\end{tabular}

Table 4. The coefficients of the $2^{\text {nd }}$ position curve of the $2^{\text {nd }}$ joint

\begin{tabular}{|c|c|c|c|c|c|}
\hline Intervals [s] & $q_{4}[\mathrm{rad}]$ & $q_{3}[\mathrm{rad}]$ & $q_{2}[\mathrm{rad}]$ & $q_{1}[\mathrm{rad}]$ & $q_{0}[\mathrm{rad}]$ \\
\hline$[0.0000,2.3806)$ & -0.0032 & 0.0156 & 0.0000 & 0.0000 & 0.3491 \\
\hline$[2.3806,3.5057)$ & 0.0071 & -0.0822 & 0.3493 & -0.5543 & 0.6790 \\
\hline$[3.5057,4.2751)$ & -0.0116 & 0.1797 & -1.0280 & 2.6645 & -2.1421 \\
\hline$[4.2751,6.6127)$ & 0.0044 & -0.0941 & 0.7280 & -2.3400 & 3.2066 \\
\hline$[6.6127,7.8886)$ & -0.0085 & 0.2460 & -2.6457 & 12.5325 & -21.3803 \\
\hline$[7.8886,10.2557)$ & 0.0032 & -0.1229 & 1.7198 & -10.4260 & 23.8975 \\
\hline
\end{tabular}

Table 5. Stetting for external disturbances and uncertainties and starting points

\begin{tabular}{lcccc}
\hline & \multicolumn{2}{c}{ External disturbances and uncertainties } & \multicolumn{2}{c}{ Starting points [rad] } \\
\cline { 2 - 5 } & The $1^{\text {st }}$ position curve & The $2^{\text {nd }}$ position curve & The 1st position curve & The 2 ${ }^{\text {nd }}$ position curve \\
\hline The $1^{\text {st joint }}$ & $10 \exp \left(-2(t-5)^{2}\right)$ & $10 \sin (t)$ & 0.02 & -0.34 \\
\hline The $2^{\text {nd }}$ joint & $2 \exp \left(-0.5(t-5)^{2}\right)$ & $2 \cos (t)$ & 0.52 & 0.34 \\
\hline
\end{tabular}

ideal trajectories in each period accords with Eq. (28), a reference trajectory formula.

$$
y=q_{4} t^{4}+q_{3} t^{3}+q_{2} t^{2}+q_{1} t+q_{0} .
$$

The setting for the uncertainties and external disturbances and starting points for the four kinds of control methods is shown in Table 5. The parameter setting for the three sliding mode methods is shown in Table 6 . The boundary layer thickness of the fuzzy controller is taken as $1 \times 10^{-5}$. The control parameters of the PID are as follows: $K_{p}=5000, K_{i}=500$, $K_{d}=2000$. The design of the two-DOF manipulator in this paper is as follows: $m_{1}=m_{2}=2, r_{1}=1, r_{2}=0.8$, $g=9.8[29]$.
Table 6. Parameter setting for the three sliding modes

\begin{tabular}{|c|c|c|c|c|c|}
\hline Methods & $p$ & $q$ & $\eta$ & $\beta_{1}$ & $\beta_{2}$ \\
\hline FETSM & 5 & 3 & \multirow{3}{*}{0.2} & \multirow{3}{*}{1} & \multirow{3}{*}{1} \\
\hline ETSM & 5 & 3 & & & \\
\hline ESM & 1 & 1 & & & \\
\hline
\end{tabular}

The trajectory-tracking situation of the above four control methods is shown in Figs. 3 to 6, demonstrating that all four control methods can effectively implement the trajectory-tracking task and meet the basic requirements of practical application. According to Fig. 3, it is found that the tracking trajectories by the ETSM and the proposed FETSM coincide with the ideal trajectories with only slight 

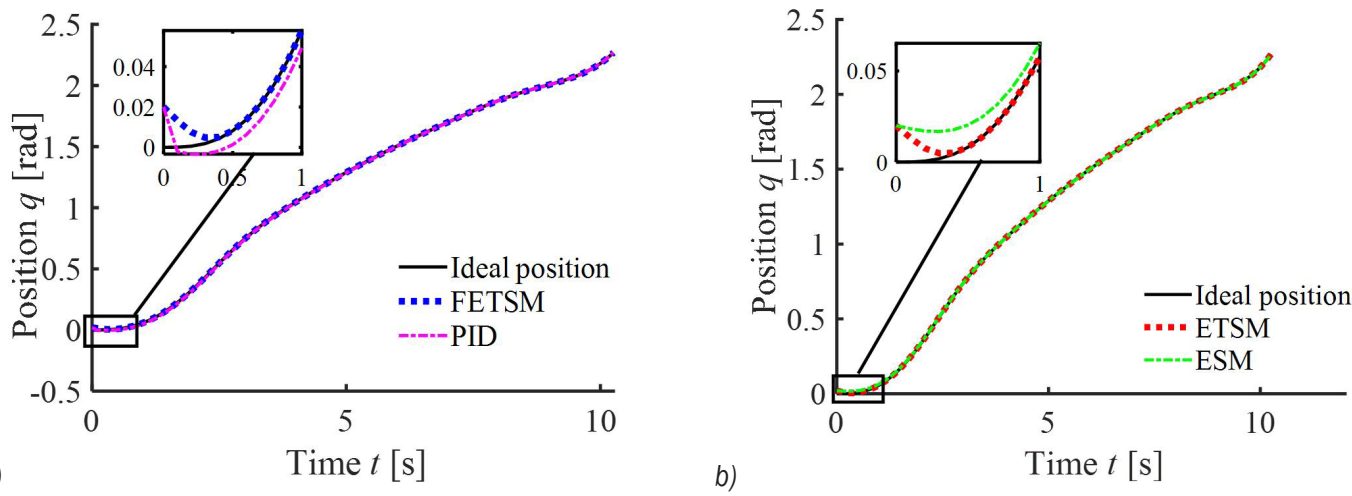

Fig. 3. Tracking situation of the $1^{\text {st }}$ position curve of the 1st joint; a) FETSM and PID; b) ETSM and ESM

deviation in the initial stage. The phenomenon in Fig. 3 is similar to those in Figs. 4 to 6 . However, the tracking trajectories by the ESM and PID have some obvious deviation from the ideal trajectories in some different periods. In order to further compare the control precision of the four methods, their tracking errors are quantitatively analysed by calculating the ordinate difference between the actual trajectories and the ideal ones at the same time and the same joint.
The averages of the tracking error are shown in Table 7. For the $1^{\text {st }}$ curve, compared with the ETSM, the average error of the $1^{\text {st }}$ joint by the proposed FETSM is increased by $1.88 \%$, and the average error of the $2^{\text {nd }}$ joint is reduced by $15.33 \%$; compared with the ESM, those errors are reduced by $81.13 \%$ and $94.20 \%$ respectively; compared with the PID, those error is reduced by $88.58 \%$ and $93.17 \%$ respectively. As for the $2^{\text {nd }}$ curve, compared with the ETSM, the
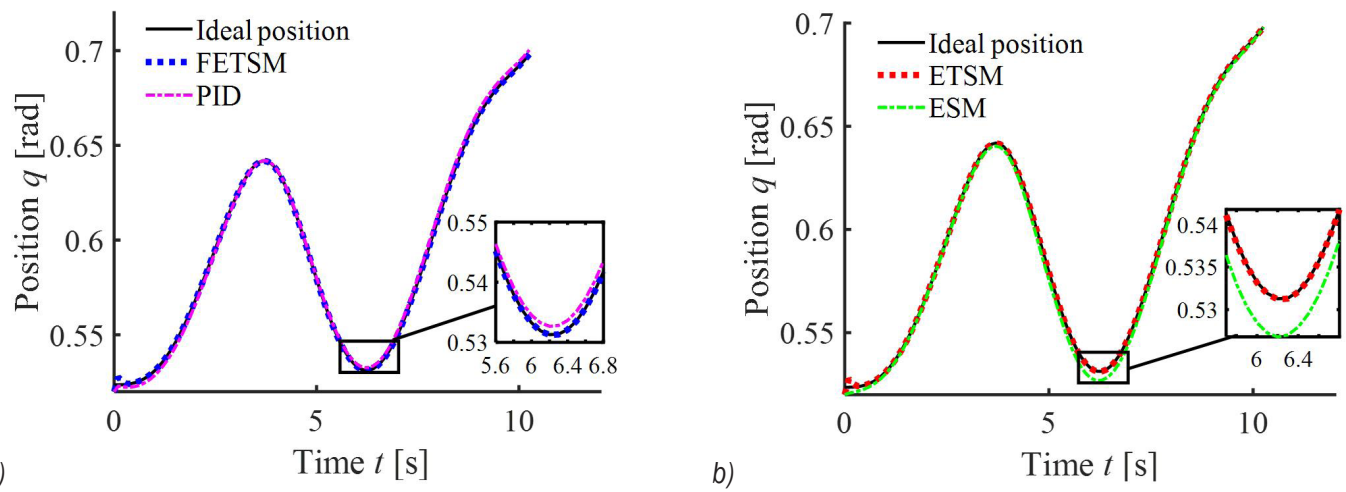

Fig. 4. Tracking situation of the 1 st position curve of the $2^{\text {nd }}$ joint; a) FETSM and PID; b) ETSM and ESM

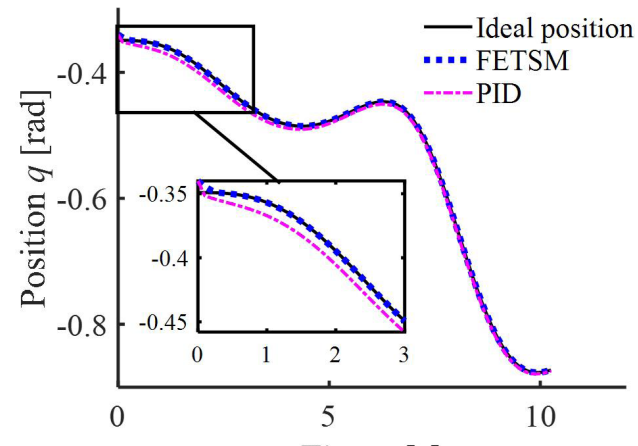

a)

Time $t[\mathrm{~s}]$

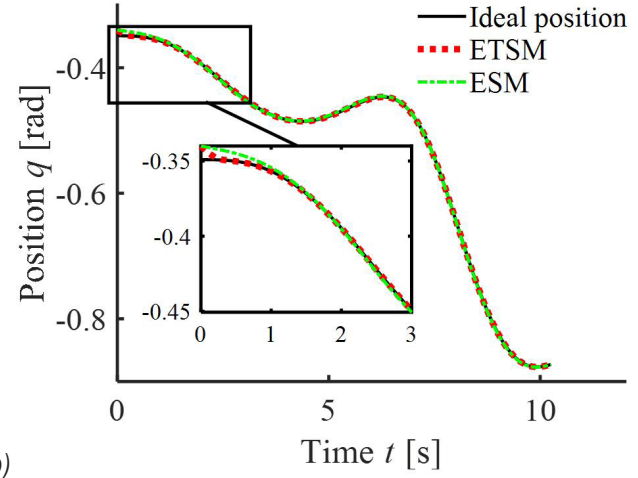

b)

Fig. 5. Tracking situation of the $2^{\text {nd }}$ position curve the 1st joint; a) FETSM and PID; b) ETSM and ESM 

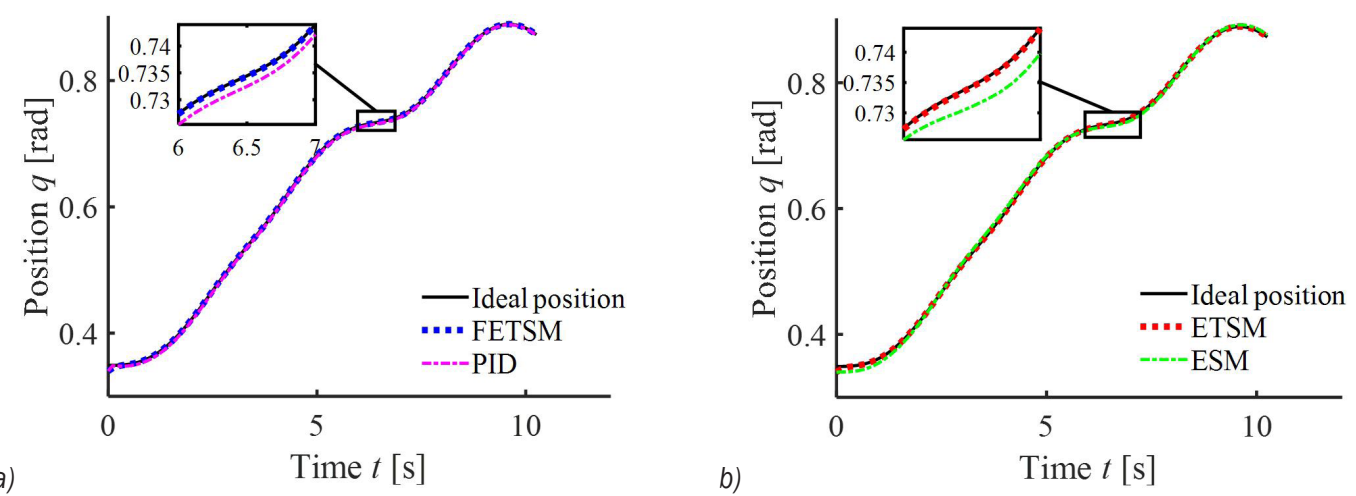

Fig. 6. Tracking situation of the $2^{\text {nd }}$ position curve of the 2nd joint; a) FETSM and PID; b) ETSM and ESM

Table 7. The averages of tracking error

\begin{tabular}{|c|c|c|c|c|}
\hline Control methods & $\begin{array}{l}\text { The } 1^{\text {st }} \text { curve \& the } 1 \text { st joint } \\
{[\mathrm{rad}]}\end{array}$ & $\begin{array}{l}\text { The } 1 \text { st curve } \& \text { the } 2^{\text {nd }} \text { joint } \\
\text { [rad] }\end{array}$ & $\begin{array}{l}\text { The } 2^{\text {nd }} \text { curve } \& \text { the } 1 \text { st joint } \\
\text { [rad] }\end{array}$ & $\begin{array}{l}\text { The } 2^{\text {nd }} \text { curve \& the } 2^{\text {nd }} \text { joint } \\
{[\text { [rad] }}\end{array}$ \\
\hline FETSM & $4.34 \times 10^{-4}$ & $1.16 \times 10^{-4}$ & $2.11 \times 10^{-4}$ & $2.14 \times 10^{-4}$ \\
\hline ETSM & $4.26 \times 10^{-4}$ & $1.37 \times 10^{-4}$ & $1.70 \times 10^{-4}$ & $2.79 \times 10^{-4}$ \\
\hline ESM & $2.30 \times 10^{-3}$ & $2.00 \times 10^{-3}$ & $1.40 \times 10^{-3}$ & $3.40 \times 10^{-3}$ \\
\hline PID & $3.80 \times 10^{-3}$ & $1.70 \times 10^{-3}$ & $6.00 \times 10^{-3}$ & $2.00 \times 10^{-3}$ \\
\hline
\end{tabular}

average error of the 1 st joint by the proposed FETSM is increased by $24.12 \%$, and the average error of the $2^{\text {nd }}$ joint is reduced by $23.30 \%$; compared with the ESM, those errors are reduced by $84.93 \%$ and 93.71 $\%$ respectively; compared with the PID, those error is reduced by $96.43 \%$ and $89.30 \%$, respectively.

In brief, the precision of the proposed FETSM dealing with the 1 st joint is less than that of the ETSM, but the average error of the overall joints is reduced by $3.56 \%$ compared with the latter; compared with the ESM and PID, the FETSM can reduce the average error of the overall joints by $89.30 \%$ and $92.78 \%$, respectively. As a result, the proposed FETSM has better control precision compared with the other three methods.

The variation of the tracking error of joints 1 and 2 with time was shown in Fig. 7. The proposed FETSM is superior to the PID in error convergence speed and robustness. To compare the error convergence speed and robustness of three sliding mode methods, taking the error by the ESM at $1 \mathrm{~s}$ as the reference, the convergence time of the four curves by the proposed FETSM to achieve the reference error is $0.195 \mathrm{~s}, 0.260 \mathrm{~s}, 0.175 \mathrm{~s}$, and $0.045 \mathrm{~s}$, respectively; and that by the ETSM is $0.195 \mathrm{~s}, 0.260 \mathrm{~s}, 0.175 \mathrm{~s}$, and $0.047 \mathrm{~s}$, respectively. On the $2^{\text {nd }}$ position curve of the $2^{\text {nd }}$ joint, the error convergence speed by the FETSM is slightly better than that by the ETSM; in other cases, the error convergence time by the proposed
FETSM is consistent with that by the ETSM. Moreover, the average speed of the error convergence by the above two is $83.13 \%$ faster than that by the ESM. The averages of the maximum error caused by disturbances in the three sliding mode methods are shown statistically in Table 8. It shows that the robustness of the proposed FETSM is less than that of the ETSM in the 1st joint but better than the latter in the 2nd joint. The robustness of the FETSM is superior to that of the ESM in joints 1 and 2. The averages of the overall disturbance error by the FETSM, the ETSM and ESM are $9.39 \times 10^{-5}, 1.35 \times 10^{-4}$, and $2.96 \times 10^{-3}$, respectively. In short, the overall robustness of the proposed FETSM is $30.24 \%$ higher than that of the ETSM, and $96.83 \%$ higher than that of the ESM. It can be seen from the above analysis that the proposed FETSM can ensure sufficient error convergence speed and robustness.

\subsection{Analysis of Input Torque}

In order to investigate the anti-chattering performance of the FETSM, the input torque characteristics of the different control systems, in the same joint and in the same position curve, are analysed. The ETSM, which has better trajectory-tracking precision than the ESM, is selected as a competitive sample of non-fuzzy control; the PID is selected as a competitive sample of non-sliding mode control. The comparison diagrams 
for the input torques using the three methods are shown in Figs. 8 to 11.

As shown in Fig. 8a, there is chattering with an amplitude of approximately $10.24 \mathrm{~N} \cdot \mathrm{m}$ by the proposed FETSM in the period of $0 \mathrm{~s}$ to $0.55 \mathrm{~s}$, but the input torque curve is smooth and continuous in other times. Combined with Fig. 7a, it is found that the error by the proposed FETSM converges to $0 \mathrm{~s}$ near 0.55 $\mathrm{s}$, and the system reaches the sliding mode surface. Therefore, the reason for the chattering in the initial stage is that the system does not reach the sliding mode surface. The phenomenon in Fig. 8a is similar to those in Figs. 9a, 10a and 11a using the same the FETSM.

As shown in Fig. 8b, the chattering amplitude of the input torque curve by the ETSM is small in the period of $4.9 \mathrm{~s}$ to $5.1 \mathrm{~s}$; in other periods, it is about
$10.20 \mathrm{~N} \cdot \mathrm{m}$. Currently, the disturbance term applied to the joint is Gaussian and reaches the maximum in $5 \mathrm{~s}$. Obviously, the chattering amplitude of the system decreases only when the disturbance term approaches the switching term. The phenomenon in Fig. $8 \mathrm{~b}$ is similar to those in Figs. 9b, $10 \mathrm{~b}$ and $11 \mathrm{~b}$. Quantitatively comparing and analysing the chattering time of the systems by the ETSM and FETSM in the four cases shown in Figs. 8 to 11, The chattering time of these two methods is shown in Table 9. It is found that those by the proposed FETSM is less than those by the ETSM, can be reduced by $94.75 \%$ on average.

As shown in Fig. 8c, the input torque curve using the PID is consistent with the proposed FETSM except that serious chattering occurs in the overshoot stage. The phenomenon in Fig. $8 \mathrm{c}$ is similar to those in Figs. 9c, 10c and 11c. Quantitatively comparing and
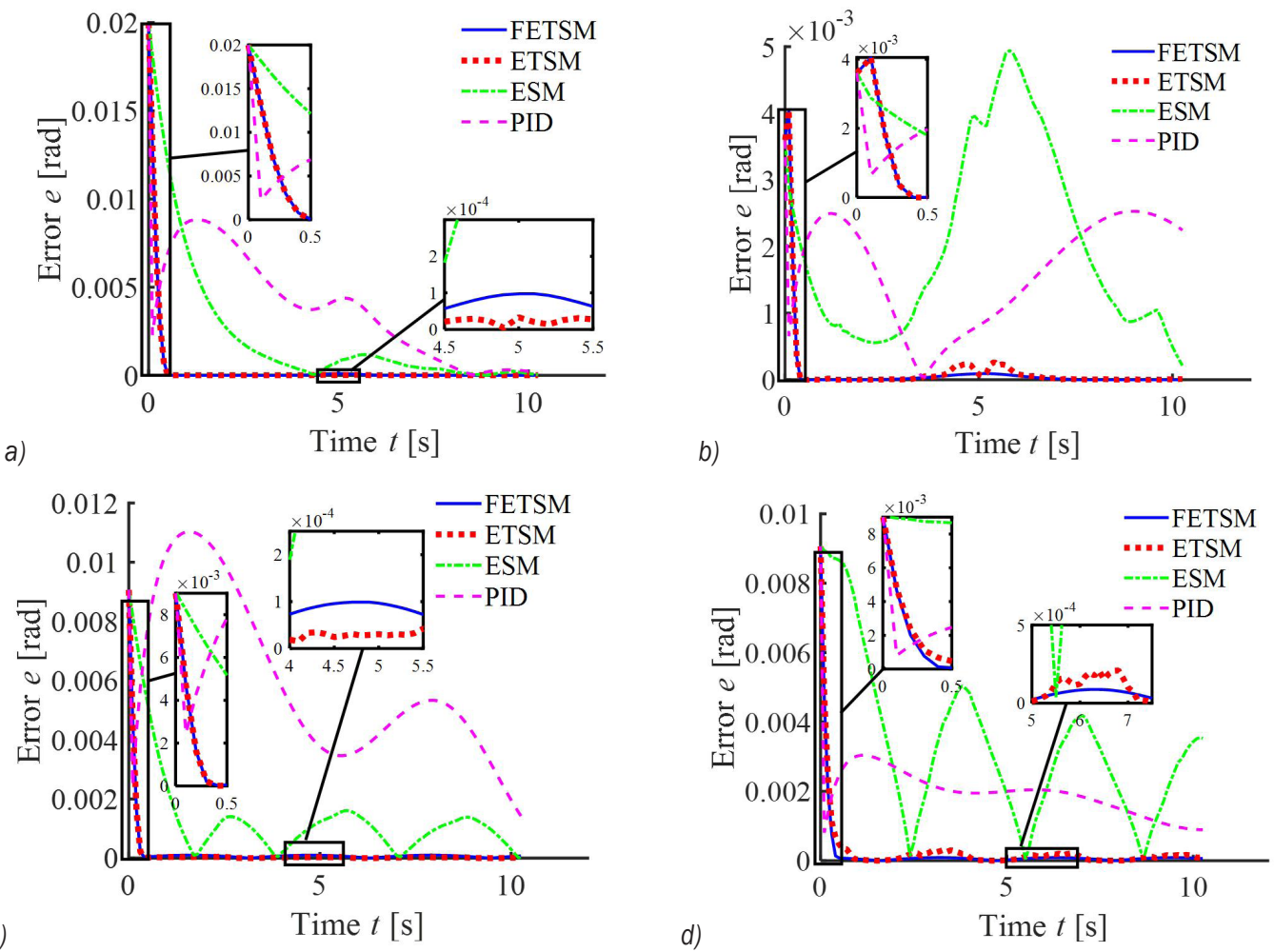

Fig. 7. Variation of the error of joints; a) the 1 st position curve of the 1 st joint; $b$ ) the 1 st position curve of the $2^{\text {nd }}$ joint; c) the $2^{\text {nd }}$ position curve of the 1 st joint; $d$ ) the $2^{\text {nd }}$ position curve of the 2 nd joint

Table 8. The averages of the maximum error caused by disturbances

\begin{tabular}{|c|c|c|c|c|}
\hline Control methods & $\begin{array}{l}\text { The 1st curve \& the } 1 \text { st joint } \\
\text { [rad] }\end{array}$ & $\begin{array}{l}\text { The 1st curve \& the } 2^{\text {nd }} \text { joint } \\
\text { [rad] }\end{array}$ & $\begin{array}{l}\text { The } 2^{\text {nd }} \text { curve \& the } 1 \text { st joint } \\
{[\text { [rad] }}\end{array}$ & $\begin{array}{l}\text { The } 2^{\text {nd }} \text { curve \& the } 2^{\text {nd }} \text { joint } \\
{[\mathrm{rad}]}\end{array}$ \\
\hline FETSM & $9.74 \times 10^{-5}$ & $9.17 \times 10^{-5}$ & $9.84 \times 10^{-5}$ & $8.79 \times 10^{-5}$ \\
\hline ETSM & $3.31 \times 10^{-5}$ & $2.53 \times 10^{-4}$ & $3.03 \times 10^{-5}$ & $2.22 \times 10^{-4}$ \\
\hline ESM & $1.18 \times 10^{-3}$ & $4.94 \times 10^{-3}$ & $1.46 \times 10^{-3}$ & $4.25 \times 10^{-3}$ \\
\hline
\end{tabular}


analysing the chattering amplitude of the systems by the PID and FETSM in the four cases shown in Figs. 8 to 11 , The maximum amplitudes of these two methods are shown in Table 10. It is found that those by the proposed FETSM is less than those by the PID, can be reduced by $99.21 \%$ at least.
Moreover, compared with similar methods proposed by other scholars [1], the proposed FETSM can achieve similar anti-chattering performance while the structure of the switching term is simple.

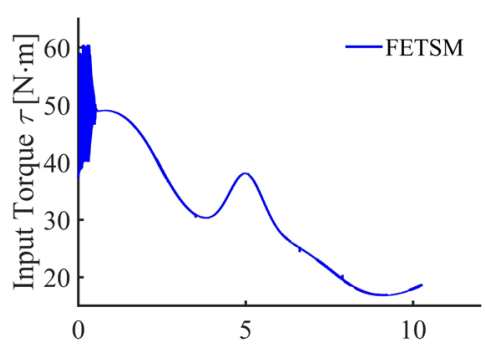

a)

Time $t[\mathrm{~s}]$

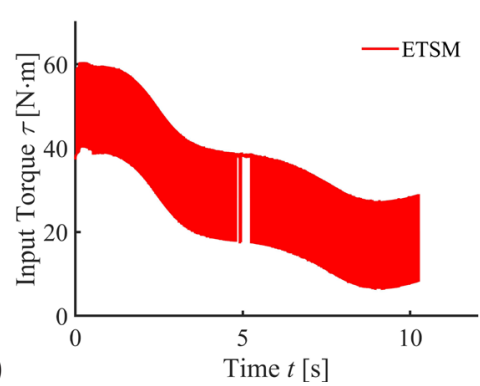

b)

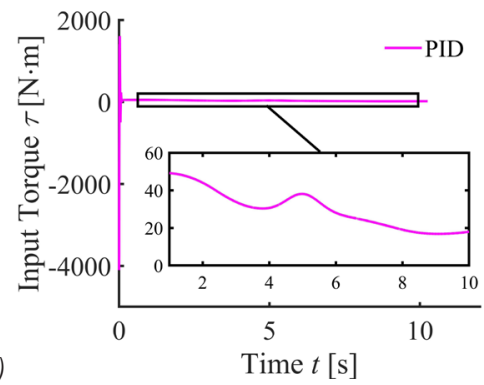

Fig. 8. Input torque comparison of the 1st position curve of the 1st joint; a) FETSM; b) ETSM; c) PID
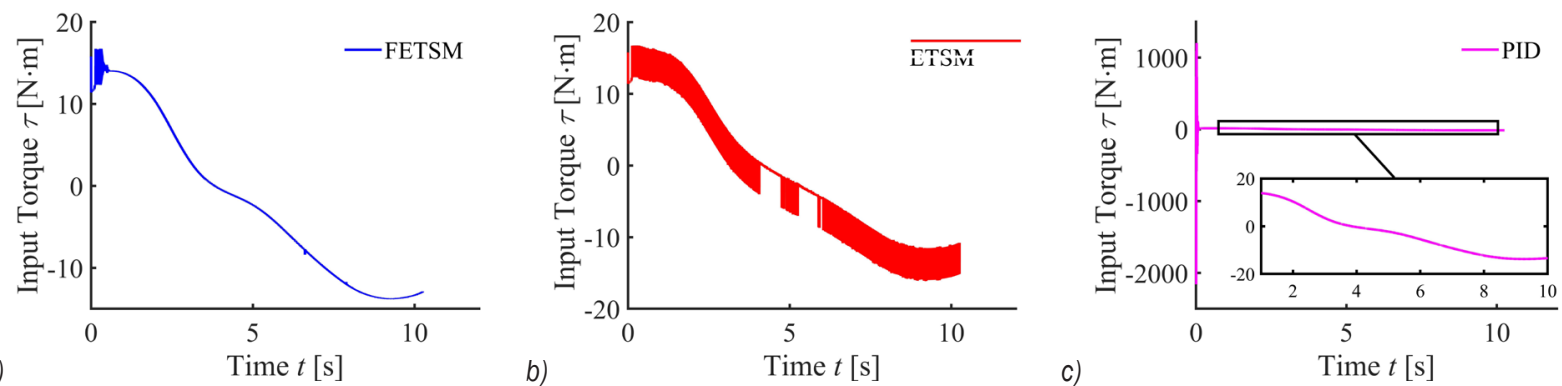

Fig. 9. Input torque comparison of the 1 st position curve of the $2^{\text {nd }}$ joint; a) FETSM; b) ETSM; c) PID
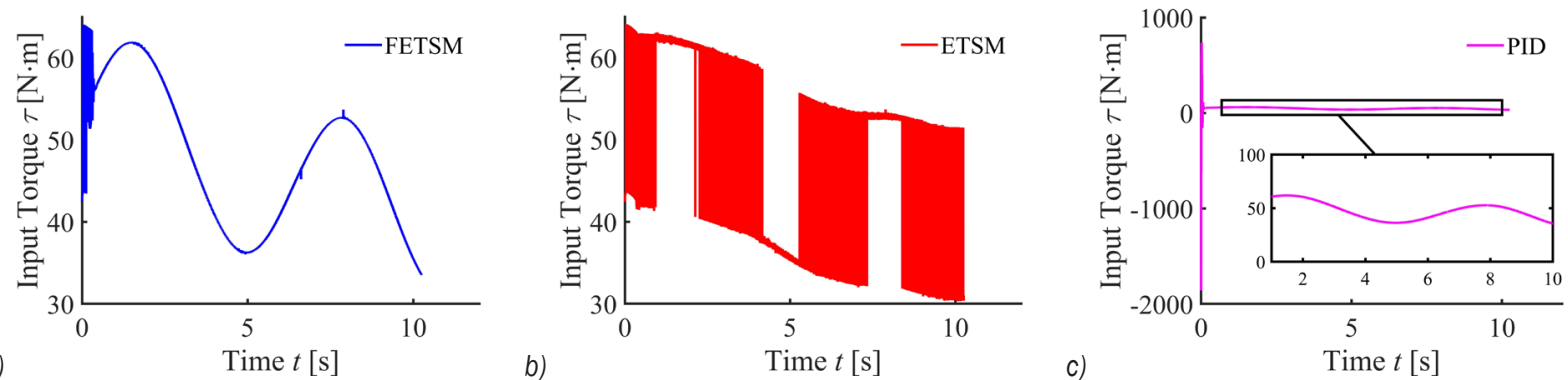

Fig. 10. Input torque comparison of the $2^{\text {nd }}$ position curve of the 1st joint; a) FETSM; b) ETSM; c) PID

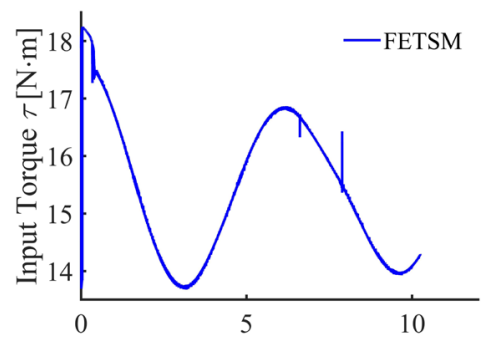

a)

Time $t[\mathrm{~s}]$

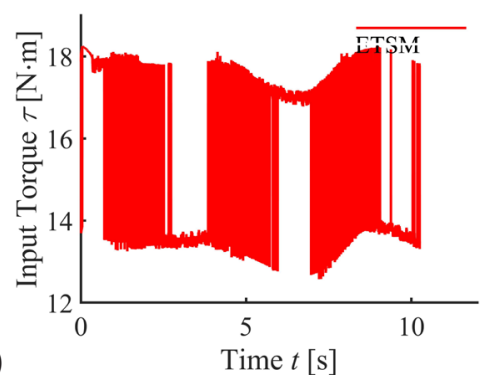

b)

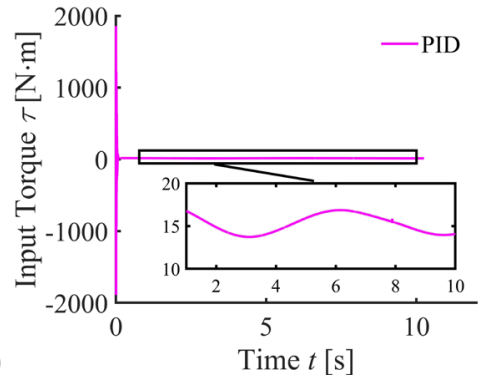

c)

Fig. 11. Input torque comparison of the $2^{\text {nd }}$ position curve of the $2^{\text {nd }}$ joint; a) FETSM; b) ETSM; c) PID 
Table 9. The chattering time of the FETSM and ETSM

\begin{tabular}{|c|c|c|c|c|}
\hline Control methods & $\begin{array}{l}\text { The } 1^{\text {st }} \text { curve \& the } 1 \text { st joint } \\
{[\mathrm{s}]}\end{array}$ & $\begin{array}{l}\text { The } 1^{\text {st }} \text { curve \& the } 2^{\text {nd }} \text { joint } \\
{[\mathrm{s}]}\end{array}$ & $\begin{array}{l}\text { The } 2^{\text {nd }} \text { curve \& the } 1 \text { st joint } \\
{[\mathrm{s}]}\end{array}$ & $\begin{array}{l}\text { The } 2^{\text {nd }} \text { curve \& the } 2^{\text {nd }} \text { joint } \\
{[\mathrm{s}]}\end{array}$ \\
\hline FETSM & 0.55 & 0.58 & 0.42 & 0.11 \\
\hline ETSM & 9.67 & 8.81 & 6.76 & 6.76 \\
\hline
\end{tabular}

Table 10. The maximum amplitudes of the FETSM and PID

\begin{tabular}{ccccc}
\hline Control methods & $\begin{array}{c}\text { The 1st curve \& the 1st joint } \\
{[\mathrm{N} \cdot \mathrm{m}]}\end{array}$ & $\begin{array}{c}\text { The 1st curve \& the 2nd joint } \\
{[\mathrm{N} \cdot \mathrm{m}]}\end{array}$ & $\begin{array}{c}\text { The 2nd curve \& the 1st joint } \\
{[\mathrm{N} \cdot \mathrm{m}]}\end{array}$ & $\begin{array}{c}\text { The 2nd curve \& the 2nd joint } \\
{[\mathrm{N} \cdot \mathrm{m}]}\end{array}$ \\
\hline FETSM & 10.24 & 2.21 & 10.26 & 2.22 \\
\hline PID & $2.85 \times 10^{3}$ & $1.6810^{3}$ & $1.3010^{3}$ & $1.8710^{3}$ \\
\hline
\end{tabular}

\section{CONCLUSIONS}

(1) The proposed FETSM control method can be used to track the actual motion position of each joint according to the ideal trajectory of the corresponding joint. This technology can be used to suppress the chattering of manipulators under heavy-load operations.

(2) Simulation results show that compared with the ETSM, the overall tracking precision by the proposed FETSM is improved by $3.56 \%$, and the overall robustness is improved by $30.24 \%$. Moreover, their error convergence speeds are basically the same. Compared with the ESM, the overall tracking precision by the proposed FETSM is improved by $89.30 \%$, the overall robustness is improved by $96.83 \%$, and the error convergence speed is improved by 83.13 $\%$. Compared with the PID, the overall tracking precision by the proposed FETSM is improved by $92.78 \%$. Moreover, its error convergence speed and overall robustness are better than those by the PID. Consequently, the proposed FETSM can obtain sufficient trajectory-tracking precision, error convergence speed and robustness.

(3) Employing the proposed FETSM, chattering occurs only when the system does not reach the sliding mode surface. Compared with the ETSM, the proposed FETSM can reduce the chattering time by $94.75 \%$ on average. Compared with the PID, the maximum chattering amplitude by the FETSM can be reduced by $99.21 \%$ at least. Therefore, the proposed FETSM can reduce the chattering of systems, and optimize the input torque control.

\section{ACKNOWLEDGEMENTS}

This work was supported by the Natural Science Research Project of Higher Education of Anhui Province of China [grant numbers KJ2020A0357] and the University Synergy Innovation Program of Anhui Province of China [grant numbers GXXT-2019-048].

\section{REFERENCES}

[1] Wu A.G., Wu S.H., Dong N. (2019). Non-singular fast terminal sliding model fuzzy control of robotic manipulators. Journal of Zhejiang University (Engineering Science), vol. 53, no. 5, p. 862-871, D0I:10.3785/j.íssn.1008-973X.2019.05.006.

[2] Liu, P., Liu, Y.H., Wang, K., Wei, X.X., Xin, C., Wu, X.L. (2020). Design and Performance Analysis of Airbag-Soft-Manipulator According to Characteristic Parameters. Strojniški vestnik Journal of Mechanical Engineering, vol. 66, no. 1, p. 38-50, DOI:10.5545/sv-jme.2019.6228.

[3] Fang, L.X., Wang, T., Wang, P.J., Hou, C.X., Wu, M. (2021). Kinematic cooperative optimization control algorithm for underground heavy-load robot. Journal of Intelligent \& Robotic Systems, Journal of intelligent \& robotic systems, vol. 102, no. 11, p. 1-15, D0l:10.1007/s10846-021-01360-y.

[4] Alam, W., Mehmood, A., Ali, K., Javaid, U., Alharbi, S., Iqbal, J. (2018). Non-linear control of a flexible joint robotic manipulator with experimental validation. Strojniški vestnik Journal of Mechanical Engineering, vol. 64, no. 1, p. 47-55, DOI:10.5545/sv-jme.2017.4786.

[5] Wang, Y.Y., Yan, F., Jiang, S.R., Chen, B. (2020). Adaptive non-singular terminal sliding mode control of cable-driven manipulators with time delay estimation. International Journal of Systems Science, vol. 51, no. 8, p. 1429-1447, D0l:10.1080 /00207721.2020.1764659.

[6] Kumar, N., Rani, M. (2021). Neural network-based hybrid force/position control of constrained reconfigurable manipulators. Neurocomputing, vol. 420, no. 3, p. 1-14, DOI:10.1016/j.neucom.2020.09.009.

[7] Shojaei, K., Kazemy, A., Chatraei, A. (2021). An observerbased neural adaptive PID2 controller for robot manipulators including motor dynamics with a prescribed performance. 
IEEE/ASME Transactions on Mechatronics, vol. 26, no. 3, p. 1689-1699, DOI:10.1109/TMECH.2020.3028968.

[8] Zhang, Y.Y., Kim, D.G., Zhao, Y. D., Lee, J.M. (2020). PD control of a manipulator with gravity and inertia compensation using an RBF neural network. Transactions on Control, Automation and Systems Engineering, vol. 18, no. 12, p. 3083-3092, D0I:10.1007/S12555-019-0482-X.

[9] Liang, X.F., Yang, B. (2011). PID track following control of a 7-DOF manipulator based on ADAMS. Advanced Materials Research, vol. 1380, no. 636, p. 694-597, D0l:10.4028/www. scientific.net/AMR.317-319.694.

[10] Elkhateeb, N.A., Badr, R.I. (2017). Novel PID tracking controller for 2DOF robotic manipulator system based on artificial bee colony algorithm. Electrical, Control and Communication Engineering, vol. 13, no. 1, p. 55-62, Dol:10.1515/ecce-20170008.

[11] Haidegger, T., Kovács, L., Precup, R-E., Preitl, S., Benyó, B., Zoltán Benyó, Z. (2011). Cascade control for telerobotic systems serving space medicine. IFAC Proceedings Volumes, vol. 44, no. 1, p. 3759-3764, D0l:10.3182/20110828-6IT-1002.02482.

[12] Neghreian, E., Koofugar, H.R., (2021). Robust tracking control of robot manipulators with friction and variable loads without velocity measurement: A switched control strategy. Proceedings of the Institution of Mechanical Engineers, Part I: Journal of Systems and Control Engineering, vol. 235, no. 4, p. 532-539, DOI:10.1177/0959651820947944.

[13] Izadbakhsh, A, Khorashadizadeh, S. (2020). Robust adaptive control of robot manipulators using Bernstein polynomials as universal approximator. International Journal of Robust and Nonlinear Control, vol. 30, p. 2719-2735, D0l:10.1002/ rnc.4913.

[14] Liu, F.C., Liang, L.H., Li, Q., Wang, W.K. (2014). Sliding mode control for space manipulator trajectory tracking considering effects of gravity. Control and Decision, vol. 29, no. 10, p. 1856-1860, Dol:10.13195/j.kzyjc.2013.0764. (in Chinese)

[15] Jiang, S., Tian, F.Q., Sun, S.Y., Liang, W.G. (2020). Integrated guidance and control of guided projectile with multiple constraints based on fuzzy adaptive and dynamic surface. Defence Technology, vol. 16, no. 6, p. 1130-1141, DOI:10.1016/j.dt.2019.12.003.

[16] Xi, L.P., Chen, Z.L., Qi,X.H. (2012). Fast sliding mode variable structure control for manipulators with chattering suppression effect. Electric Machines and Control, vol. 16, no. 7, p. 97102, D0l:10.15938/j.emc.2012.07.002. (in Chinese)

[17] Tran, M.D., Kang, H.J. (2016). A novel adaptive finite-time tracking control for robotic manipulators using non-singular terminal sliding mode and RBF neural networks. International journal of precision engineering and manufacturing, vol. 17, no. 7, p. 863-870, D0I:10.1007/s12541-016-0105-x.

[18] Chang, Y.F., Yuan, R.Y., Tan, X.M., Yi, J.Q. (2016). Observerbased adaptive sliding mode control and fuzzy allocation for aero and reaction jets' missile. Proceedings of the
Institution of Mechanical Engineers Part I - Journal of Systems and Control Engineering, vol. 230, no. 6, p. 498-511, DOI:10.1177/0959651816629540.

[19] Wan, M., Tian. Q.G., Wang, M.C. (2018). adaptive sliding mode control of robot manipulator based on second order approximation accuracy and decomposed fuzzy compensator. Wireless Personal Communications, vol. 103, no. 2, p. 1207 1218, DOI:10.1007/s11277-018-5421-2.

[20] Feng, Y., Yu, X.H., Man, Z.H. (2002). Non-singular terminal sliding mode control of rigid manipulators. Automatica, vol. 38, no. 12, p. 2159-2167, D0l:10.1016/S0005-1098(02)00147-4.

[21] Wang, T.L., Tan, N.L., Zhang, X.W., L.i., G.Z., Su, S.Q., Zhou, J., Qiu, J.Z., Wu, Z.Q., Zhai, Y.K., Labati, RD, Piuri, V., Scotti, F. (2021). A time-varying sliding mode control method for distributed-mass double pendulum bridge crane with variable parameters. IEEE ACCESS, vol. 9, no. 5, p. 75981-75992, DOI:10.1109/ACCESS.2021.3079303.

[22] Cheng, C., Lai, R., Chen, Z., Liu, X.D. (2016) Adaptive nonsingular terminal sliding mode control of 6-DOF manipulator with modified switch function. Journal of Advanced Computational Intelligence and Intelligent Informatics, vol. 20, no. 2, p. 294-301, D0I:10.20965/jaciil.2016.p0294.

[23] Shahri, E.S.A., Balochian, S. (2015). Analysis of fractionalorder linear systems with saturation using Lyapunov' s second method and convex optimization. International Journal of Automation and Computing, vol. 12, no. 4, p. 4440-4447, DOI:10.1007/s11633-014-0856-8.

[24] Lv, Z.Y., Zhang, Y., Yu, M., Xia, Y.H.. (2020). Decentralised coordinated energy management for hybrid AC/DC microgrid by using fuzzy control strategy. IET Renewable Power Generation, vol. 14, no. 14, p. 2649-2656, Dol:10.1049/ietrpg. 2019.1281.

[25] Precup, R.-E., Preitl, S. (2003). Development of fuzzy controllers with non-homogeneous dynamics for integral-type plants. Electrical Engineering, vol. 85, no. 3, p. 155-168, DOl:10.1007/s00202-003-0157-7.

[26] Li, Y. (2021). Anhui Polytechnic University School of Mechanical Engineering, from https://github.com/ LiYi199983/-fuzzycontrol, accessed on 2021-08-28.

[27] Liang, X.C., Wan, Y., Zhang, C.G., Kou, Y.Y. Xin, Q.Q., Yi, W. (2018). Robust position control of hydraulic manipulators using time delay estimation and non-singular fast terminal sliding mode. Proceedings of the Institution of Mechanical Engineers, Part l: Journal of Systems and Control Engineering, vol. 232, no. 1, p. 50-61, D0l:10.1177/0959651817733596.

[28] Liu, T.R. (2019). Quadratic feedback-based equivalent sliding mode control of wind turbine blade section based on rigid trailing-edge flap. Measurement \& Control, vol. 52, no. 1-2, p. 81-90, DOI:10.1177/0020294018819548.

[29] Li, Y. (2021). Anhui Polytechnic University School of Mechanical Engineering, from https://github.com/LiYi199983/FETSMmatlab-simulink, accessed on 2021-08-16. 